

\title{
Editorial
}

\section{The vaccination debate}

\author{
Malcolm Boyle $\mathrm{PhD}^{1}$
}

\author{
Affiliation: \\ ${ }^{1}$ Monash University, Victoria
}

A recent decision by Ambulance Victoria (1) to require new staff to be fully vaccinated has caused some ripples in the media and some health related circles, but is it really such an issue?

The public should expect high level pre-hospital care and not be exposed to, or potentially infected with a common disease that would normally be vaccinated against, as was the case recently in Queensland, Australia. A Queensland paramedic has been accused of potentially exposing up to 4,500 people to measles (2). This has necessitated a time-consuming, and therefore expensive, follow up of the people potentially exposed.

Should pre-hospital care organisations provide appropriate vaccinations for their existing workforce if they have not had them previously, to protect them, their families, colleagues and the general public against vaccine-preventable diseases? Is it not reasonable to expect new employees to be fully vaccinated, especially in healthcare organisations? Monash University in Victoria, Australia, for example, expects healthcare students to be fully vaccinated prior to attending their clinical placements (3), thereby ensuring paramedic students meet the new employment requirements of Ambulance Victoria.

There is a potential issue with people who are allergic to components of the vaccine or who are vaccinated but do not develop immunity. These people should not be discriminated against because they do not develop immunity to the vaccine or are unable to be vaccinated. This point requires ongoing debate to determine a course of action in the event of actual/potential exposure, based on scientific evidence.

The vaccination debate raises many issues including one where a worker may refuse to work with a colleague because they have not been vaccinated. The above mentioned issue highlights a potentially complex problem for a healthcare organisation including the safety and protection of their workforce and potentially the general public.

There has been an ongoing scare campaign by the anti-vaccination lobby about the adverse effects of vaccinations, however these adverse effects are very rare with the greater good of vaccinations for the broader community far outweighing any adverse effects. Decisions about vaccinating healthcare and related staff needs to be based on scientific evidence and not anecdotal and hearsay evidence.

In this issue is an interview with George McCary by Brett Williams about Freedom House, an early version of an emergency medical service in Pittsburgh, United States of America (USA) (4). There are also two commentaries about the content of this interview by Walt Stoy from Pittsburgh University (5), USA and Peter O'Meara from Latrobe University in Victoria (6), Australia. The article by Blackhall and Edwards is one of the first articles reporting on allergic/anaphylaxis reactions from a paramedic perspective in Tasmania (7). The article by Mulholland and colleagues looks at the critical incident technique and how it can be used in the research process and specifically what areas of the work environment may be benefit from the technique (8). The article by Barraclough investigates the most appropriate pre-hospital treatment for cyanide poisoning, the findings are also relevant to fire fighter first responders given the presence of cyanide in closed environment fires (9). The final article by Thompson and colleagues is about the integration of a capstone topic in the Bachelor of Paramedic Science degree at Flinders University, South Australia (9).

Dr Mal Boyle

Editor

Australasian Journal of Paramedicine 


\section{References}

1. Butt C. No jab, no job for future ambos. The Age. 11 June 2015.

2. Remeikis A. Measles outbreak sparks Queensland Health staff mandatory immunisation. ibid. 20th May 2015.

3. Vaccination and Immunisation Guidelines. Monash University, Faculty of Medicine, Nursing and Health Sciences; 2015.

4. Williams B. Freedom House: a rich history and a continuing legacy: An interview with George McCary. Australasian Journal of Paramedicine 2015;12(3).

5. Stoy W. Freedom House: a rich history and a continuing legacy: An interview with George McCary. Australasian Journal of Paramedicine 2015;12(3).

6. O'Meara P. Freedom House: a rich history and a continuing legacy: An interview with George McCary. Australasian Journal of Paramedicine 2015;12(3).

7. Blackhall M, Edwards D. Incidence and patient demographics of pre-hospital anaphylaxis in Tasmania. Australasian Journal of Paramedicine 2015;12(3).

8. Mulholland P, Barnett T, Woodroffe J. Critical Incident Technique - A useful method for the paramedic researcher's toolkit. Australasian Journal of Paramedicine 2015;12(3).

9. Barraclough C. Is There An Ideal Prehospital Drug Treatment For Acute Cyanide Poisoning? Australasian Journal of Paramedicine 2015;12(3). 